\title{
An assessment of tree species dynamics in rural farmland of Nepal
}

\begin{abstract}
D. K. Kharal ${ }^{1}$ and B. N. Oli ${ }^{2}$
Dynamics of species distribution, species composition and species number are very important areas to be understood for sustainable management of forest and tree resources. The paper endeavours to solicit information on dynamics of tree species in terms of their composition and number, and also assesses the relationship between socio-economic factors and tree species dynamics. The study was conducted through survey of 98 sampled households, focus group discussion and direct field observation. Species composition and species number of tree resources of the study area are identified for different time period. The study found out that proportion of tree species loss on farmland was higher than that of species introduction. Similarly, 20 species were found with very limited distribution in the study area while two of them are already under the threatened category at the national level. The reasons for species change in the farmland are also identified. Farmers are now attracted to grow fast growing, multipurpose and easily available tree species. Economic return is the major concern for them. Such a situation may lead to further loss of tree species from the farmland. Some species such as Shorea robusta and Phyllanthus emblica, which were among the widely distributed in the beginning, are now about to be lost because of easy availability in nearby forest, slow growth rate and limited uses.
\end{abstract}

Key Words: Composition, Diversity, Dynamics, Farmland, Socioeconomic factors, Trees.

$\mathbf{T}$ he destruction and degradation of forests is now recognized as one of the greatest environmental threats and tragedies of all times (Bist 1999). Environmental degradation is one of the major challenges in Nepal as well and deforestation is mainly responsible for this. Biodiversity has a significant role not only in sustaining livelihoods of Nepalese people, but also in environmental conservation. The forest and trees provide a vast array of goods and services to human beings (Arnold 1991; Das and Oli 2001; Kanel 1995; Suresh Kumar and Ramasamy 2003). Despite such benefits, many species have been lost and biodiversity is reduced from the deforestation process especially in the natural forest.

Agriculture is the mainstay of economy in the country as agriculture and forestry together has 39.3\% contribution in total gross domestic product of the country (HMGN 2002). Dwindling of forest resources at an annual rate of $1.7 \%$ over fifteen years period from 1978/79 to 1994 (DFRS 1999) and growing demand for forest products has motivated the local people to grow trees on their farmland. Tree growing on farmland is gaining ground in the country as it provides immediate benefits and utilities to the rural people in sustaining their livelihoods. Tree planting initiatives on degraded land in Asia are often politically driven and aspire to achieve both economic and environmental benefits (Sayer et al. 2004). The growing markets for tree products have encouraged farmers to grow trees on their private farmland (Malla 1993; Kanel 1995; Das and Oli 2001).

Changes in composition and number of tree species in rural farmland are widely noticed over a time. Naturally grown tree species were common in the past and farmers were just maintaining them as it was. Farming practices are being changed gradually. More recently, planted trees are replacing the naturally grown tree species. Large and big tree species are being replaced by small and manageable size of tree species. Single use tree species are being replaced by multipurpose tree species. Some fast growing tree species for timber, fuelwood and furniture are also being introduced rapidly in the farm.

Inappropriate agricultural methods, indiscriminate and injudicious harvest of natural resources, fragmented population of species and introduction of alien species have all led to both quantitative and

\footnotetext{
${ }^{1}$ Forest Survey Officer, Department of Forest Research and Survey, P. O. Box 3339, Kathmandu, Nepal, Email: dkharal@wlink.com.np

${ }^{2}$ Forest Research Officer, Department of Forest Research and Survey, P. O. Box 3339, Kathmandu, Nepal, Email: bn_oli@yahoo.com
} 
qualitative depletion of biodiversity (Bist 1999). The threat of erosion of high levels of genetic diversity in many traditionally managed agroecosystems is a current conservation concern, motivating studies of how diversity can be maintained by in-situ conservation measures (Alvarez et al. 2004). Similarly, traditional agro-forestry system of the farmland are being modified or destroyed because of many reasons such as fragmentation of land, land tenure right, socio-economic change, introduction of alien species and climatic change as well. In this context, this paper aims at investigating the dynamics of tree species on farmland and also assessing the impact of socio economic factors on dynamics of tree species.

\section{Materials and Methods}

\section{Study Area}

Birendranagar Village Development Committee (VDC) area of the Chitwan district was selected for this study. The village is characterized with diverse community structure and various land use type and different settlement period so that comparison among the different categories of each socio-economic variable can be analyzed easily. The community is diverse particularly in terms of ethnic group, time of settlement, economic level and occupation. The village has natural forest mainly dominating by Shorea robusta forest some part of which are managed by community forest user groups and remaining are controlled by government agency itself. East-west national highway of the country touches in southern part of the village with semi urban characteristics whereas typical rural settlements and natural forest are found in northern part.

\section{Methods}

Secondary data were gathered through Village Development Committee Office, District Forest Office, Central Bureau of Statistics and other concerned offices, and also from various literatures. Primary data were obtained through household survey and focus group discussion. The fieldwork of the area took about six months and observed the community structure, land use type, vegetation composition, structure and dynamics, and other socio-economic condition of the area. Formal household survey of 98 households was conducted with a semi-structured questionnaire. First the Distribution of household number in each VDC unit (ward) was obtained from the VDC office and numbers of sample households were divided accordingly. A stratified sampling was developed to identify the location for sample survey and then responses were obtained through random walk sampling. The first household was selected randomly. An interval of 20 households along the walk was maintained to avoid bias in responses and to obtain as much diversity in the responses as possible. Field observations were done simultaneously to assess the distribution of tree species inside the farmland. In this way, the sample covered $5 \%$ of the households in the study area.

During the field observation of each sampled household farm, all the tree species and their number of individuals were counted regardless of their age. Few group discussions were also conducted at the local level to crosscheck and validate the information obtained from household survey. Problems and constraints in the area, suggestions and recommendations for the future improvement were taken during the group discussion.

For quantitative analysis, the gathered data were entered into computer and analysed through Excel and Minitab software whereas subjective and logical interpretation was made for qualitative analysis.

\section{Results and Discussion}

\section{Dynamics of Tree Species in Rural Farmland}

Biological environment is the most versatile element of the earth. It changes in terms of number, composition and distribution over the period. Changes occur sometime because of ecological processes and sometimes by human interference. Changes of trees and forest resources were found in both natural forest stand and cultivated/farmland in the study area. Forest is the main source of tree species in the farmland, even though many of them are already domesticated. Useful and economical tree species are generally preferred by farmers and other species might be lost particularly from farmers' land. Economic benefit either in the monetary term or in other indirect form is the major driving force to determine the species type to be held by the farmers in their farmland.

Table 1 shows the list of top 10 tree species distributed in highest number of households at present time and at settled time. Melia azederach and Mangifera indica are found in farmland of majority households at present. Both of them are multipurpose tree species. Artocarpus heterophyllus, fruit 
Table 1: List of widely distributed tree species in the study area

\begin{tabular}{|c|c|c|c|c|c|c|}
\hline \multirow[b]{2}{*}{$\mathrm{SN}$} & \multirow{2}{*}{$\begin{array}{l}\text { Widely distributed } \\
\text { species at present }\end{array}$} & \multicolumn{4}{|c|}{ Percent of households with species holding } & \multirow{2}{*}{$\begin{array}{c}\text { Widely distributed } \\
\text { species at settled } \\
\text { time }\end{array}$} \\
\hline & & At present & 5 years ago & $\begin{array}{c}10 \text { years } \\
\text { ago }\end{array}$ & $\begin{array}{c}\text { At the } \\
\text { beginning }\end{array}$ & \\
\hline 1 & Melia azederach & $60 \quad(1)$ & $29(4)$ & $3(10)$ & $0(48)$ & Shorea robusta \\
\hline 2 & Mangifera indica & $60 \quad(2)$ & $50(16)$ & $41(26)$ & $13(44)$ & Terminalia belerica \\
\hline 3 & Artocarpus heteropbyllus & $44(38)$ & $39(37)$ & $28(32)$ & $5 \quad(44)$ & Garuga pinnata \\
\hline 4 & Dalbergia sissoo & $43 \quad(5)$ & $36 \quad(5)$ & $9 \quad(7)$ & $3 \quad(38)$ & Terminalia tomentosa \\
\hline 5 & Psidium guyajava & $39(29)$ & $30(29)$ & $16(28)$ & $9 \quad(35)$ & Gmelina arborea \\
\hline 6 & Garuga pinnata & $38 \quad(0)$ & $37(13)$ & $32(13)$ & $44(35)$ & Ficus religiosa \\
\hline 7 & Dendrocalamus spp & $35 \quad(0)$ & $37 \quad(0)$ & $22(1)$ & $18(34)$ & Dillenia pentagyna \\
\hline 8 & Leucaena leucocephala & $33 \quad(1)$ & $21 \quad(0)$ & $6 \quad(3)$ & $\begin{array}{ll}1 & (32) \\
\end{array}$ & Phyllanthus emblica \\
\hline 9 & Prunus persica & 31 (3) & 15 (3) & $6 \quad(7)$ & $0 \quad(32)$ & $\begin{array}{l}\text { Stereopermum } \\
\text { tetragonum }\end{array}$ \\
\hline 10 & Gmelina arborea & $29(17)$ & $28(17)$ & $28(21)$ & $35(31)$ & Ficus glomerata \\
\hline
\end{tabular}

Source: Field survey

Note: 1. Left side figure in the table corresponds to the distribution of tree species presented in column 2

2. Figure in parentheses corresponds to the distribution of tree species presented in last column.

tree, is held by about 44 percent of the total household but its distribution was less at the beginning of the settlement and so is the case for Dalbergia sissoo. Dalbergia sissoo and Melia azedarach dominate the whole distribution of tree numbers, covering about three-fourth of the total tree number. Both of them are primarily used for timber/furniture and fuelwood purpose. Dalbergia sissoo alone represents more than half of the total tree numbers. Melia azederach is further used for fodder particularly for goat. Karki (1994) found similar result in the Chitwan and Rupandehi district, central Terai of Nepal. They have mentioned that among the 20 tree species prevalent in the two districts, D. sissoo was more widely grown than any other native or exotic tree, representing 50 percent of the total number of trees planted. Das (1999) has also found the Mangifera indica, Artocarpus heterophyllus, Dalbergia sissoo and Psidium guyajava as the most widely distributed tree species on the farmland in eastern Terai of Nepal. Das and Oli (2001) found that sissoo was one of the most widely distributed species, mainly grown on the homestead farmland and bunds at the edges of farmland. The study carried out in India indicated that Poplar is the most preferred tree species for planting on farmland followed by Eucalyptus spp and Dalbergia sissoo (Pant et al. 1999).

At the beginning of the settlement, Shorea robusta was distributed in highest number among households followed by Terminalia belerica, Garuga pinnata, and Terminalia tomentosa respectively. T. tomentosa and $T$. belerica are the close associates of the Shorea robusta forest. Garuga pinnata and Gmelina arborea are still exist in large number of households comparatively. Among the widely distributed tree species at present, 40 percent are fruits and their presence was less at the time of settlement. There was only one fruit species named Pbyllanthus emblica at the beginning and rests were other types. More than half of the widely distributed species are fodder categories and its abundance was about 80 percent at the beginning. Regarding timber/furniture trees, it also occupies 40 percent of the top 10 having same position as beginning. Tree species that are principally used for fuelwood purpose is also about 40 percent. Because of the multiple uses of some tree species, they are counted in all types separately so that sum does not become 100 percent. All trees can be used as fuelwood. Farmers usually do not plant fuelwood species separately, even though few species are recognized as the best one.

Garuga pinnata and Gmelina arborea are one of the widely distributed tree species of the farmland found in both the times; viz. settled and present time. Both of them are good fodder. Garuga pinnata is easily propagated by vegetative means, which may be reasons why it is so common. Further, it is branchy and produces lot of fodder in a year. Its size is not so big due to which even women and children can lop it. Gmelina arborea is good for fodder, fuelwood and furniture as well. It also does not have negative interaction with crop in high level. Their roots also do not compete with crops because of deep root system.

One species was completely lost from the area, which was widely distributed at beginning. Dillenia pentagyna is now confined only in the nearby forest. 


\section{Distribution of Tree Species}

Distribution of tree species type in different period is presented in Table 2. A total of 60 tree species were recorded in the study area. The highest number of tree species was found around 5 years ago. After then, species number started to decline. Some tree species with few numbers were already there in the farm when early settlers were granted land for permanent settlement. All of them were naturally grown and found scattered all over the farm. There were more than 25 different tree species found on private farmland in the study village of Chitwan district, 20 in Sunsari and 12 in Kanchanpur district (Das and Oli 2001). Study from Bangladesh revealed that farmers always try to incorporate as many tree species as possible in their homesteads to establish a sustainable productive system (Mohiuddin et al. 1997).

\section{Species Loss and Introduced}

Establishment of two brick industries in the VDC was mainly responsible for the loss of large number of trees as well as species especially from ward number $6,7,8$ and 9 . Since brick industry consumes lot of woods, it is now easy to sell trees from the farm. The industry buys any kind of trees for the kiln regardless of quality. Since then, some households have sold trees for earning money. Continuation of this situation might reduce the species diversity and species richness of the area.

The diversity of fruit species is increased over time in the farm while diversity of other species type is decreased. It was found in China that farmers, forest farms and forestry authorities are actively engaged in the expansion of fruit and nut trees and bamboo plantations, which are considered more profitable than conventional timber plantations (Ruiz Perez et al. 2004). Changes of the fodder species diversity is not big while tremendous changes have been observed in timber/furniture species. During the period of cultivation, some tree species were completely lost from the farmland and some new species are introduced. Rate of changes may be different in different period depending on the socioeconomic and ecological factors. Table 3 shows the figure of lost and introduced tree species in the farmland of the study area.

Average lost and average introduced tree species in the farm is almost equal with somewhat different level of standard deviation. New species generally replace the old one. Characteristics of the tree species mainly determine their existence in the farm. For example, trees were large at the beginning while they are small and manageable at present. Table 4 shows the list of lost tree species from the farmland area.

Since the beginning of the settlement, 14 new tree species have been introduced in the farmland while 26 other species have completely been lost. Maximum number of lost species and introduced species by a household was 24 and 21 respectively. Among the introduced tree species, more than half were fruits followed by fodder species and timber/furniture species respectively. On the other hand, fruit species, fodder species and timber/furniture species were lost by 12,41 and 41 percent respectively.

Less number of fruit tree species were lost compared to others. In total, the number of lost and introduced tree species are almost in balance though timber/ furniture tree species were lost about 41 percent and only 7 such kind of tree species were introduced in the farm. Farmers managed to hold all the fruit

Table 2: Distribution of tree species by time series

\begin{tabular}{|l|c|c|c|c|c|c|}
\hline \multirow{2}{*}{ Time Series } & \multicolumn{5}{|c|}{ Distribution of tree species by time series in percentage } \\
\cline { 2 - 7 } & Fruit spp. & $\begin{array}{c}\text { Timber/furniture } \\
\text { spp. }\end{array}$ & $\begin{array}{c}\text { Fodder } \\
\text { spp. }\end{array}$ & $\begin{array}{c}\text { Fuelwood } \\
\text { spp. }\end{array}$ & $\begin{array}{c}\text { Other } \\
\text { spp. }\end{array}$ & $\begin{array}{c}\text { Total spp } \\
\text { number }\end{array}$ \\
\hline At present & 32 & 12 & 58 & 15 & 12 & 60 \\
\hline 5 years before & 22 & 15 & 54 & 18 & 12 & 72 \\
\hline 10 years before & 27 & 17 & 52 & 18 & 6 & 71 \\
\hline At beginning & 16 & 17 & 61 & 17 & 9 & 69 \\
\hline
\end{tabular}

Source : Field survey

Table 3: Analysis of species lost and introduced in the study area

\begin{tabular}{l|c|c|c|c|}
\hline Category of spp. & Average & Minimum & Maximum & Standard Deviation \\
\hline Lost & 6,02 & 0 & 24 & 7,13 \\
\hline Introduced & 6,03 & 0 & 21 & 4,64 \\
\hline P - value & 0,991 & & \\
\hline Result & Highly insignificant \\
Source : Field survey
\end{tabular}


Table 4: List of lost tree species from the study area

\begin{tabular}{|c|c|c|c|c|c|}
\hline S.N. & Local Name & Scientific Name & $\begin{array}{c}\% \text { of } \mathrm{HH} \text { with } \\
\text { Spp till } 5 \text { years } \\
\text { back }\end{array}$ & $\begin{array}{c}\% \text { of } \mathrm{HH} \text { with } \\
\text { Spp till } 10 \text { years } \\
\text { back }\end{array}$ & $\begin{array}{l}\% \text { of } \mathrm{HH} \text { with } \\
\text { Spp at beginning }\end{array}$ \\
\hline 1 & Bodhdhayero & Lagerstroemia parviflora & 0.0 & 2.2 & 19.5 \\
\hline 2 & Dar & Boehmeria rugulosa & 0.0 & 0.0 & 2.6 \\
\hline 3 & Dudhilo & Ficus nemoralis & 1.0 & 0.0 & 1.3 \\
\hline 4 & Karang & Pongamia pinnata & 4.1 & 3.3 & 11.7 \\
\hline 5 & Karma & Adina cordifolia & 0.0 & 1.1 & 10.4 \\
\hline 6 & Khari & Celtis australis & 0.0 & 0.0 & 1.3 \\
\hline 7 & Koiralo & Baubinia veriegata & 0.0 & 0.0 & 1.3 \\
\hline 8 & Kumhi & Careya arborea & 0.0 & 0.0 & 1.3 \\
\hline 9 & Patke & Gaultharia hookaris & 1.0 & 0.0 & 5.2 \\
\hline 10 & Palans & Butea monosperma & 0.0 & 4.4 & 27.3 \\
\hline 11 & Kusum & Schleichera trijuga & 1.0 & 2.2 & 13.0 \\
\hline 12 & Lampate & Duabanga grandiflora & 1.0 . & 1.1 & 1.3 \\
\hline 13 & Latikath & Cornus oblonga & 0.0 & 0.0 & 2.6 \\
\hline 14 & Rudhilo & Pogostemon glaber & 0.0 & 0.0 & 1.3 \\
\hline 15 & Sandan & Ongenia dalbergioides & 2.1 & 1.1 & 1.3 \\
\hline 17 & Siris & Albizia spp & 0.0 & 8.9 & 2.6 \\
\hline 18 & Tantari & Dillenia pentagyna & 0.0 & 1.1 & 33.8 \\
\hline 19 & Valayo & Rhus wallicbii & 0.0 & 2.2 & 18.2 \\
\hline 20 & Teak & Tectona grandis & 1.0 & 0.0 & 0.0 \\
\hline 21 & Rabar & Ficus elastica & 1.0 & 0.0 & 0.0 \\
\hline 22 & Phaledo & Erithrina arborescens & 1.0 & 1.1 & 0.0 \\
\hline 23 & Masala & Eucalyptus spp & 3.1 & 3.3 & 0.0 \\
\hline 24 & Kalkiphool & Callistemon viminalis & 1.0 & 0.0 & 0.0 \\
\hline 25 & Ashok & Saraca indica & 1.0 & 0.0 & 0.0 \\
\hline 26 & Pakhuri & Ficus glaberrima & 0.0 & 1.1 & 2.6 \\
\hline
\end{tabular}

Source: Field survey

species for the last 10 years. Instead, 50 percent new fruit species have been introduced. More fodder species were lost than their introduction until then. In addition, the situation was almost same for timber/ furniture tree species. There was almost balance between the lost and introduced tree species in total for the last 10 years. Nevertheless, large numbers of tree species were introduced for the last 5 years. Situation in the farmland changed afterward. From 5 years back to now, more species were lost compared to introduction of new species in the area. If the trend continues, further loss of tree species is expected from the farm.

\section{Socio-economic Impact on Species Dynamics}

Socio-economic factors might not alone determine the species changes but it is the significant one in rural farmland situation. Farmers' decisions mainly determine which species to be retained and which one to be cleared from their farm. Some ecological factors may affect to some extent for species change. The impacts of socio-economic factors on species dynamics in rural farmland are presented in Table 5.

Farm size, homegarden size, household size, income level, livestock size and settlement period have significant impact on species dynamics. Number of species lost and species introduced is different in each category of these factors. Level of species changes continuously increases as the farm size increases and so is the case with income level and homegarden size. It is also found that larger and wealthier farmer in Bangladesh tended to plant more trees on their farmland than poorer farmers (Hocking et al. 1996). Das and Oli (2001) also found a positive correlationship between landholding and tree growing in all the three studied districts of Nepal. Although the impact of level of fuelwood consumption is not significant, the trend shows that higher changes occurred in high consumption level and lower changes occurred in lower consumption level. The situation is also similar for level of forest visit. Business based household have introduced more tree species than other category of households (Table 5). Lowest species change occurred in labour-based household-farm. Caste does not have any significant impact on species changes though loss of species is lowest in lower caste. As the settlement period increases level of species changes also increases. Long duration of settlement allows farmers to change the species composition frequently. Generally, the late settlers should spend some years just to introduce the species in the farm. 
Table 5: Impact of socio economic factors on species change

\begin{tabular}{|c|c|c|c|}
\hline Variables & Categories of variables & Average of species lost & $\begin{array}{l}\text { Average of species } \\
\text { introduced }\end{array}$ \\
\hline Farm size & Small - Medium - Large & $\begin{array}{l}3,36-8,00-8,22 \\
(\mathrm{P}=0,001 *)\end{array}$ & $\begin{array}{l}3,89-7,00-10,44 \\
\left(\mathrm{P}=0,000^{*}\right)\end{array}$ \\
\hline Homegarden & Small - Medium - Large & $\begin{array}{l}4,80-7,18-11,50 \\
\left(\mathrm{P}=0,026^{*}\right)\end{array}$ & $\begin{array}{l}3,72-8,96-13,62 \\
\left(\mathrm{P}=0,000^{*}\right)\end{array}$ \\
\hline Household size & Small - Medium - Big & $\begin{array}{l}4,94-10,37-5,34 \\
\left(\mathrm{P}=0,026^{*}\right)\end{array}$ & $\begin{array}{l}4,44-7,81-6,65 \\
\left(\mathrm{P}=0,023^{*}\right)\end{array}$ \\
\hline Livestock size & Small - Medium - Large & $\begin{array}{l}3,82-4,73-8,70 \\
\left(\mathrm{P}=0,012^{*}\right)\end{array}$ & $\begin{array}{l}3,56-5,50-8,10 \\
\left(\mathrm{P}=0,000^{*}\right)\end{array}$ \\
\hline $\begin{array}{l}\text { Fuelwood } \\
\text { consumption }\end{array}$ & Low - Medium - High & $\begin{array}{l}4,56-5,87-9,00 \\
\left(\mathrm{P}=0,080^{* *}\right)\end{array}$ & $\begin{array}{l}4,51-6,31-8,20 \\
\left(\mathrm{P}=0,013^{*}\right)\end{array}$ \\
\hline Forest visit & Less - Fair - High & $\begin{array}{l}5,59-5,91-10,00 \\
\left(\mathrm{P}=0,307^{* *}\right)\end{array}$ & $\begin{array}{l}6,38-5,23-7,00 \\
\left(\mathrm{P}=0,445^{* *}\right)\end{array}$ \\
\hline Forest distance & Near - Fair - Far & $\begin{array}{l}5,51-6,40-6,35 \\
\left(\mathrm{P}=0,839^{* *}\right)\end{array}$ & $\begin{array}{l}5,04-6,67-6,88 \\
\left(\mathrm{P}=0,205^{* *}\right)\end{array}$ \\
\hline $\begin{array}{l}\text { Fuelwood collection } \\
\text { time }\end{array}$ & Quick - Fair - Late & $\begin{array}{l}5,67-5,95-6,59 \\
\left(\mathrm{P}=0,903^{* *}\right)\end{array}$ & $\begin{array}{l}6,17-5,25-7,54 \\
\left(\mathrm{P}=0,155^{* *}\right)\end{array}$ \\
\hline Income level & Low - Medium - High & $\begin{array}{l}4,51-9,12-6,50 \\
\left(\mathrm{P}=0,005^{*}\right)\end{array}$ & $\begin{array}{l}4,34-8,09-8,87 \\
\left(\mathrm{P}=0,000^{*}\right)\end{array}$ \\
\hline Income source & $\begin{array}{l}\text { Agriculture- Labor - Business - } \\
\text { Pension - Service }\end{array}$ & $\begin{array}{l}7,64-2,73-5,66-4,82- \\
6,90\left(\mathrm{P}=0,127^{* *}\right)\end{array}$ & $\begin{array}{l}7,47-3,42-7,66-4,05- \\
6,70\left(\mathrm{P}=0,004^{*}\right)\end{array}$ \\
\hline Caste & $\begin{array}{l}\text { Brahmin - Chhetri - Others - } \\
\text { Lower }\end{array}$ & $\begin{array}{l}4,52-8,60-7,48-1,33 \\
(\mathrm{P}=0,097 * *)\end{array}$ & $\begin{array}{l}6,21-8,30-5,15-7,00 \\
\left(\mathrm{P}=0,265^{* *}\right)\end{array}$ \\
\hline Settlement time & Early - Middle - Late & $\begin{array}{l}7,31-1,76-0,50 \\
\left(\mathrm{P}=0,002^{*}\right)\end{array}$ & $\begin{array}{l}6,51-6,07-1,25 \\
\left(\mathrm{P}=0,008^{*}\right)\end{array}$ \\
\hline
\end{tabular}

Source: Field survey

Note: $1{ }^{*}$ significant $2 .{ }^{* *}$ not significant

\section{Risk of Species Loss and Its Sustainability}

Distribution of species and their individual number determine the possible loss or extinction of species from the area. Widely distributed species are less vulnerable to be lost or extinct whereas less distributed species are threatened to be lost from the area. If species is distributed either in large number of household farms or in large number of individual in the area, they are said to be widely distributed. They are comparatively safe for not to be lost. Once the species is found either in limited number of households or in limited number of individual, they are referred as threatened species to be lost. There is high risk with these species. They can be lost from the area in near future. Here, list of threatened species is prepared based on their distribution in number of farm and number of individual. Table 6 below presents the species name, which are threatened to be lost from the farmland.

Shrestha and Joshi (1996) have mentioned 60 plant species of non-endemic taxa fall under various categories of threats in Nepal. Among them 22 species are rare because of their economic values as exportable items, because of their geographical range lying within human encroachments and also because of their over exploitation for local use. Among the threats, 12 species are listed under endangered category and 11 species under vulnerable category. There are 3 taxa of 'Critically Endangered', 14 of 'Endangered', 23 of 'Vulnerable', 3 of 'Nearly Threatened', 1 of 'Least Concern' and 7 of 'Data Deficient' Medicinal and Aromatic Plants (MAPs) in Nepal (Sharma et al. 2004). Farmland of the current study area preserves only two species, which are found under the threatened category in Nepal. Butea monosperma is already lost from the area. Acacia catechu and Oroxylum indicum are still found in the area with very limited distribution. Shorea robusta and Phyllanthus emblica have lost their distribution very fast from the farmland. These species will completely be lost from the farm if present trend continues. In addition, the distribution of Terminalia belerica, Stereopermum tetragomumi, Terminalia alata tree species are also decreasing rapidly in the farmland.

\section{Conclusion}

As the forest degradation continues with more restricted access to the forest, increase in the price of the wood, threats in the rural farming system, farmers responds by increasing number of trees and tree species in the various places of the farmland. Traditional agro-ecosystem (agroforestry) not only support the physical needs of the people but also 
Table 6: List of threatened tree species

\begin{tabular}{|l|l|c|c|c|c|c|}
\hline SN & \multicolumn{1}{|c|}{ Species Name } & $\begin{array}{c}\text { \% of HH } \\
\text { reporting at } \\
\text { present }\end{array}$ & $\begin{array}{c}\text { Number of } \\
\text { individuals at } \\
\text { present }\end{array}$ & $\begin{array}{c}\% \text { of HH } \\
\text { reporting till } \\
5 \text { years back }\end{array}$ & $\begin{array}{c}\% \text { of HH } \\
\text { reporting till } \\
10 \text { yrs back }\end{array}$ & $\begin{array}{c}\% \text { of HH } \\
\text { reporting at } \\
\text { beginning }\end{array}$ \\
\hline 1 & Shorea robusta & 1.0 & 2 & 4.1 & 10.0 & 48.1 \\
\hline 2 & Phyllanthus emblica & 1.0 & 1 & 0.0 & 3.0 & 32.2 \\
\hline 3 & Bassia butyracea & 1.0 & 1 & 1.0 & 0.0 & 0.0 \\
\hline 4 & Grewia subinaequalis & 1.0 & 1 & 1.0 & 1.1 & 0.0 \\
\hline 5 & Sapium insigne & 1.0 & 2 & 3.0 & 0.0 & 3.9 \\
\hline 6 & Exbucklandia populnea & 1.0 & 1 & 0.0 & 0.0 & 0.0 \\
\hline 7 & Prunus domestica & 1.0 & 1 & 0.0 & 0.0 & 0.0 \\
\hline 8 & Eugenia operculata & 2.0 & 4 & 2.0 & 5.5 & 18.1 \\
\hline 9 & Cedrela toona & 2.0 & 3 & 1.0 & 1.1 & 1.2 \\
\hline 10 & Bredelia retusa & 2.0 & 5 & 1.0 & 2.2 & 2.6 \\
\hline 11 & Terminalia belerica & 2.0 & 2 & 16.3 & 25.5 & 44.1 \\
\hline 12 & Stereopermum tetragonum & 3.1 & 4 & 3.0 & 6.6 & 32.4 \\
\hline 13 & Cocus nucifera & 3.1 & 4 & 1.0 & 0.0 & 0.0 \\
\hline 14 & Holarrhena pubescens & 3.1 & 30 & 1.0 & 2.2 & 2.6 \\
\hline 15 & Machilus odoratissima & 3.1 & 8 & 1.0 & 1.1 & 3.9 \\
\hline 16 & Terminalia tomentosa & 3.1 & 8 & 4.1 & 9.9 & 23.3 \\
\hline 17 & Oroxylum indicum & 4.1 & 7 & 4.1 & 3.3 & 22.0 \\
\hline 18 & Acacia catechu & 4.1 & 5 & 3.0 & 2.2 & 27.2 \\
\hline 19 & Cleyera ochnacea & 4.1 & 6 & 3.0 & 2.2 & 3.9 \\
\hline 20 & Spondias pinnata & 4.1 & 6 & 5.1 & 5.5 & 14.3 \\
\hline So & & & & & \\
\hline
\end{tabular}

Source: Field survey

plays vital role in conservation of significant elements of biodiversity found outside natural ecosystem. Farming systems are mixed and complex. Maintaining diversity of the species is an important aspect of traditional farming.

Twenty-six tree species were completely lost from the farm from the beginning of the settlement to date. Further, twenty species were found with very limited distribution and two of them are already under the threatened category in national level. Only 14 new species were introduced till now. Farmers are now attracted to grow fast growing, multipurpose and easily available tree species. Economic return is the major concern for them. Such a situation may lead to the further loss of tree species from the farm. Some species such as Shorea robusta and Phyllanthus emblica, which were among the widely distributed in the beginning, are now about to be lost because of easy availability in nearby forest, slow growth rate and limited uses.

Socio-economic factors were found responsible for species change from the farmland. Species changes in terms of species lost and species introduced were found influenced by farm size, homegarden size, household size, livestock size, household income and settlement period. Species changes (both lost and introduced) increases as the value of such variables increases.

\section{References}

Alvarez, N., Garine, E., Khasah, C., Dounais, E., Hossaert-McKey, M. and McKey, D. 2004. Farmers' practices, metapopulation dynamics, and conservation of agricultural biodiversity on-farm: a case study of sorghum among the Duupa in sub-sahelian Cameroon. Biodiversity and Conservation 121 (4): 533-543.

Arnold, J. E. M. 1991. Tree products in agroecosystems: economic and policy issues. Gatekeeper series No. S.A.28. International Institute for Environment and Development, London. pp. 21.

Bist, M. S. 1999. Forest cover dynamics in Nilgiri Biosphere Reserve. Indian Forester 125 (7) (6): 699706.

Das, A. N. 1999. Socio economics of bamboos in eastern Nepal. Ph. D. thesis. University of Aberdeen. UK.

Das, A. N. and Oli, B. N. 2001. Tree growing practices on farmland: an option for sustaining rural livelihoods. Banko Janakari 11 (2): 8-12.

DFRS. 1999. Forest resources of Nepal (19871998). Publication No. 74. Kathmandu, Nepal.

HMGN. 2002. The Tenth Plan (2002-2007). National Planning Commission Secretariat, His Majesty's Government of Nepal, Kathmandu, Nepal. 
Hocking, D., Hocking A. and Islam, K. 1996. Trees on farms in Bangladesh. Agroforestry Systems 33: 231-247.

Kanel, K. R. 1995. Farmer and tree linkages in the terai of Nepal. Ph. D thesis. University of Minnesota, USA.

Karki, M. B. 1994. Impact of multipurpose trees on small farm systems of Nepal. A case study of Karmaiya village.

Kumar, A., Babu, B. and Ramachandarn, U. 1999. Attitude of farmers towards agroforestry programme in Kerala. Indian Journal of Forestry 22 (2): 155-159.

Malla, Y. B. 1993. Changing role of the forest resource market: an ignored dimension of community forestry. Banko Janakari 4 (1): 28-31.

Mohiuddin, M., Chowdhury, R. M. and Mohsin, M. 1997. Species diversity in homestead agroforestry system of Chittagong District: an exploratory study. Bangladesh Journal of Forest Science 26 (1): 18-24.

Pant, K., Pandit, A., Tewari, A. and Koshyari, R. S. 1999. Agroforestry Patterns in the Tarai of central Himalaya. Indian Journal of Forestry 22 (2):123-128.
Ruiz Perez, M., Belcher, B., Fu, M. and Yang, X. 2004. Looking through the bamboo curtain: an analysis of the changing role of forest and farm income in rural livelihoods in China. International Forestry Review 6 (3-4): 306-316.

Sayer, J. A., Chokkalingam, U. and Poulsen, J. 2004. The restoration of forest biodiversity and ecological values. Forest Ecology and Management 201 (1): 3-11.

Sharma, U. R., Malla, K. J. and Uprety, R. K. 2004. Conservation and management efforts of medicinal and aromatic plants in Nepal. Banko Janakari 14 (2): 3-11.

Shrestha, T. B. and Joshi, R. M. 1996. Rare, endemic and endangered plants of Nepal. World Wildlife Fund Nepal Program, Kathmandu, Nepal.

Suresh Kumar, D. and Ramasamy, C. 2003. Role of agroforestry in the household economy of resource poor farmers. Journal of Tropical Forest Products 9 (1\&2): 97-108. 